\title{
Temas uit die kerkgeskiedenis
}

J.H. van Wyk

Dept. Dogmatologiese Vakke

HTS/PU vir CHO

POTCHEFSTROOM

\section{Inleiding}

Dit is natuurlik ' $n$ onbegonne taak om enigsins 'n poging aan te wend om ' $n$ volle beeld van twee milleniums kerkgeskiedenis voor te hou. Wat die kerkgeskiedenis van Afrika betref, leef ons tans in die periode van die derde vestiging van die kerk in Afrika. Die eerste periode was aan die begin van ons Christelike jaartelling in Noord-Afrika en het gtoot name soos Tertullianus $(+220)$, Cyprianus $(+258)$ en Augustinus $(+430)$ opgelewer. Die tweede periode was gedurende die vyftiende en sestiende eeu in Wes- en Oos-Afrika. In albei gevalle het die Christendom feitlik tot nief gegaan - iets waarna ons later weer sal verwys

In plaas daarvan om die ganse 2000 jaar kerkgeskiedenis agtereenvolgens te behandel, verkies ek eerder die metode on enkele groot temas - waarskúwende temas - toe te lig. Sodoende sal die volle geskiedenis op een of ander stadium aan die orde kom. Hierdie metode het dan ook dié voordeel dat ons onmiddellik die relevansie van die verlede vir die hede kan insien

Ek lig ses temas uit, wys op die ontstaan daarvan in die verlede en die betekenis daarvan vir die hede.

\section{Temas}

\subsection{Die introverte kerk}

Kerklike introvertisme of in homself gekeerdheid is al as een van die groot gevare van die kerk oor die wêreld aangedui. Die vroeë Nuwe-Testamentiese kerk word gekenmerk deur sy gaan-dan-heenkarakter (Matt. 28:19), sy ingaan in die hele wêreld (Mark. 16:15), sy getuienis vanaf Jerusalem deur Judea en Samaria tot aan die uiterste van die aarde (Hand. 1:8). Paulus se drie sendingreise lewer hiervan duidelike bewys.

Die kerk is gestuur in die wêreld as lig vir die wêreld en sout vir die aarde (Matt. 5:14-16). 
Natuurlik moet daar ook na binne geestelike opbou en groei plaasvind (Ef. 4:12). Hierdie innerlike groei mag egter nooit in 'n na binne gekeerdheid omslaan nie: dit mag nooit sodanig ontaard dat die kerk hom in sy katedrale en kerkgeboue, pastorieë en kantore verlustig en sy roeping na buite uit die oog verloor nie. Oordrewe kerklike selfkonsentrasie was nog nooit vir die kerk 'n gesonde onderneming nie en moes dikwels onder fel kritiek deurloop. Daar is selfs al opgemerk dat die sendingaspek van die kerk onderontwikkel is in die gereformeerde belydenis en die Dordtse Kerkorde.

Die kerk van God mag nooit losgemaak word van sy verhouding tot die koninkryk van God nie. Die kerk staan nie in diens van homself nie, maar in diens van die Godsheerskappy op aarde (Matt. 6:33). Die kerk is dus betrokke, weliswaar op unieke (kerklike) wyse, by álles wat op aarde plaasvind, van die godsdiensonderrig op skool tot die harde kontemporêre politiek. Die kerk mag hom nie op piêtistiese wyse in 'n geestelike ghetto terugtrek en maak asof dit slegs om die siel van die mens gaan en om vertroosting in sy aardse nood nie. Die kerk moet die evangelie uitdra in die volle lewe en sy profetiese getuienis onder heidene en in die samelewing laat opklink.

Iemand het in hierdie verband na 'n besonder tiperende beeld verwys. In hierdie beeld word die kerk vergelyk met 'n reddingstasie aan 'n uiters onherbergsame en rotsagtige kus, waar skepe dikwels vergaan het. Aanvanklik was die totale bemanning van die reddingstasie toegespits op die redding van drenkelinge. Later het die stasie só uitgebrei dat daar skole moes kom, daana 'n dorpsraad, nog later ontspanningsgeriewe en so het dit aangehou. Langsamerhand het 'n doelverskuiwing plaasgevind: slegs enkele entoesiaste het nog uitgegaan om drenkelinge te red terwyl die meeste mense betrokke was by die volle lewe op die nuut ontstane dorp.

Juis dit - gebrek aan sendingwerk - word as een van die redes aangevoer waarom die kerk in Noord-Afrika verdwyn en die Islam oorgeneem het en dat die kerk Romeins probeer bly het en nie werklik 'n Afrika-kerk geword het nie. Min of meer dieselfde kan gesê word van die vyftiende- en sestiende-eeuse kerk in Midde-Afrika, wat net eenvoudig verdwyn het. Die groot euwel van slawehandel in hierdie tyd is ook geredelik aanvaar en selfs teologies geregverdig!

En waarom het die gereformeerde kerke in Kenia en Angola verdwyn? Waarom regeer Marxiste vandag 'n land waar voorheen 'n bloeiende gereformeerde kerk was? Blykbaar geld die altyddurende aanwesigheid van Christus in sy kerk (Matt. 28:20) nie outomaties nie. Hy kan immers 'n liefdelose en onbekeerde kerk van sy staanplek venwyder (Op. 2:4-5). 


\subsection{Die sekulêre kerk}

Teenoor die introverte kerk staan die sekulêre kerk, die kerk wat hoin só met die wêreld en sy nood identifiseer dat hy as't ware met die wêreld saamvloei en sy eie unieke identiteit prysgee. Ook kan dit die vorm aanneem, soos tydens die Middeleeue, dat die kerk eenvoudig 'n wêreldlike regeerder word. Die kerk word dan magskerk of staatskerk of wêreldkerk. In 1077 moes die gebanvloekte koning Hendrik IV gedurende die koue winter oor die Alpe trek om kaalvoet as boeteling voor pous Gregorius VIl te Canossa (Noord-Italië) te verskyn, waar sy boete aanvaar en die ban opgehef is - só groot was die pouslike gesag destyds. Die kerk kan ook die boodskap van die evangelie op alle fronte met die wêreld kompromitteer. Hier kan gedink word aan die Tweede Wêreldoorlog toe die Duitse kerk veels te nou met Hitler se nasionaal-sosialisme saamgewerk het, of aan die Afrikaanse kerke wat veels te maklik goedkeuring verleen het aan 'n beleid van apartheid in Suid-Afrika.

Die tragiese is egter dat talle van die 'swart' kerke tans presies dieselfde fout begaan deur 'n te noue koppeling tussen die kerk en die 'swart saak' aan te bring. Die evangelie laat hom nie met die swart saak of wit saak identifiseer nie maar sny dwarsdeur alle 'sake' heen, juis omdat dit die evangelie van die koninkryk is. Wanneer 'n kerk hom oorlhaastig identifiseer met 'n bepaalde volk- of kultuursaak, politieke beleid of ekonomiese sisteem, dan gee hy daarmee sy vryheid as kerk van Christus prys: dit bring sy bestaan as kerk in gedrang; dit bring die boodskap van die evangelie as kritiese woord in aanfluiting.

Nie verniet waarsku die Bybel op baie plekke dat gelowiges nié aan hierdie wêreld gelykvormig moet word nie (Rom. 12:2, vgl. 1 Joh. 2:15, 1 Pet. 1:4). Die kerk mag nooit lid word van enige kultuur- of nie-kerklike organisasie nie. Die kerk is kérk en die kerk moet kérk bly. Wáár daar van solidariteit sprake mag wees, sal dit altyd die vorm van 'in kritiese solidariteit aanneem.

Sekularisme is 'n lewensgevaar vir die kerk en dit moet betyds onderken en behoorlik vernny word. 'n Verwêreldlikte kerk is sonder enige betekenis en effek: dit is 'n kerk wat sy vryheid in Clristus prysgegee het.

\subsection{Die dwalende kerk}

Op talle plekke in die Skrif word die kerk teen afdwalinge gewaarsku.

In die Ou Testament word daarteen gewaarsku dat die volkswil groter klem as die Godswil ontvang (Eks. 32:1-8); dat die genadeprediking die oordeelsprediking verswelg ( 1 Kon. 22:5-14); dat die kultus bekleıntoon word ten koste van die daaglikse lewe (Amos 7:10-17), dat God se teenwoordigheid nie outomaties 
gewaarborg is as daar geen bekering is nie (Miga 3:5-12); dat profete broodprofete in plaas van Woordprofete is (Miga 3:11). Dit is opvallend dat 'n dogmatiese dwaling, 'n dwaling in leer, dikwels hand aan hand gaan met 'n etiese dwaling, 'n dwaling in lewe (Jes. 32:6).

Ook die Nuwe Testament is vol sulke waarskuwings teen afdwalings (Mark. 13: 6, 22; 1 Kor. 6:10; Efes. 4:4; 2 Tess. 2:11; 2 Pet. 2:18). So kan daar byvoorbeeld van die waarheid afgedwaal word (Jak. 5:20); daar kan oor die opstanding gedwaal word (1 Kor. 15:33); geldgierigheid kan 'n mens van die geloof laat afdwaal (1 Tim. 6:10); iemand kan in die dwaling (van wellus en losbandigheid) wandel (2 Pet. 2:18) - weer eens 'n etiese dimensie.

Geen wonder dan dat Christus juis die Gees van die waarheid beloof om die kerk in die hele waarheid te lei (Joh. 16:13; vgl. 1 Joh. 4:6).

Hier staan ons voor een van die grootste raaisels in die kerkgeskiedenis. Hoe moet dit verklaar word dat die een kerk van Christus, ondanks die belofte van leiding deur die Gees, tog ten prooi kon val aan soveel dwaling en afdwaling, skeuring en korrupsie? Dit sou ons hier te ver voer om op al die (veral dogmatiese) dwalinge in die kerkgeskiedenis te wys, maar dink slegs aan die stryd rondom die Godsleer (Triniteitsleer) in die eerste eeue; daanna die stryd in die Christologie (twee-nature-leer en regverdigingsleer); dié in verband met die Gees, die kerk, die Woord, die sakramente - te veel om op te noem. Juis rondom hierdie aspek - die leiding van die Gees - kon die Rooms-Katolieke Kerk die skerpste vrae aan die Reformasie stel: Kan die leiding van die Gees in die kerk só 'n laagtepunt bereik dat die kerk radikaal en totaal kan afdwaal? Of moet ons hier eerder dink aan die groot mag van die sonde en die afdwaling sien as ménslike dwaling? Of daaraan dat die leiding van die Gees nooit outomaties verstaan moet word los van bekering om nie? Vanuit hierdie hoek beskou, is geen enkele kerk, ook nie die Gereformeerde Kerke, outomaties van afdwaling gevrywaar nie. Ons staan immers voor die verstommende feit dat die GKSA, met sy suiwer reformatoriese belydenisskrifte, ver weg kon afdwaal van wat die Bybel as suiwer kerklike verhoudinge (tussen 'wit' en 'swart') sien. Ek verwys hier veral na al die omstrede besluite en optredes rondom lidmaatskap, erediensbywoning, Nagmaalviering en kanselnuil

Nog 'n aspek wat hier besonder benadruk noet word, is dat die kerk in die verlede te veel klem gelê het op dogmatiese dwalinge en te min op eticse dwalinge. Nie net die leer is belangrik nie, maar ook die Christelike lewe. Wie byvoorbeeld die eenheid van God bely, maar nie sy gebrekkige broeder help nie is op 'n dwaalweg (Jak. 2:14-19). Dit is moontlik on teoreties in die Godsleer suiwer te wees, maar in die praktyk van die lewe oor naasteliefde ver weg te dwaal. 
'n Gereformeerde kerk is 'n altyd reformerende kerk - ten opsigte van leer én lewe.

\subsection{Die konfessionalistiese kerk}

Veral as reaksie teen die dwalende kerk is daar al meer klem gelê op leersuiwerheid, die konfessie, die ortodoksie. Hierdie tendens tree veral in die periode kort na die Reformasie sterk na vore. Ons vind hier 'n meer verstandelike uitpluising en argumenterende uitbouing van die leer van die Reformasie. Die leer van die kerk moet gesagvol geformuleer word, veral die Skrifleer. Die soepelheid van die Reformasie is gaandeweg verdring deur die starheid van die Na-Reformasie: in die Skrifleer tree ' $n$ fundamentalistiese benadering na vore; die verbale inspirasieteorie word gefonmuleer en selfs die inspirasie van die vokaaltekens van die Ou Testament word bepleit (Flacius).

Daar bestaan geen twyfel nie dat die waarheid van die belydenis moet vasstaan (1 Tim. 4:6, 6:3). As daar nuwe dwalinge op die kerk afkom - byvoorbeeld apartheid as heilsweg - mag dit selfs nodig wees dat 'n nuwe belydenis oorweeg kan word. Aan 'n - redelik omvattende - Confessio Africana bestaan daar myns insiens reeds lankal meer as 'n behoefte.

Ons kan veel by die Ortodoksie leer, maar te veel aksent is gelê op sisteembou, op rasionele deurdenking, op vaste fonmules, op puritanisme. Daarom dat die Ortodoksie ook gesien word as 'n afbuiging van die Reformasie, al was die bedoeling om die Reformasie voort te sit.

Dit sou nie oordrewe wees nie om te beweer dat die GKSA oor die algemeen, miskien onbewus, meer aansluiting by die Ortodoksie as by die Reformasie gevind het en dit is jammer. Daarom moet dit werklik verwelkom word dat daar by al hoe meer gereformeerde teoloë vandag eerder na die Reformasie self teruggegryp word. Ek meen ook dat die jong Afrikaanse kerke veel vrugbaarder invloed vall die Refonmasie as van die Ortodoksie kan ondergaan. Die kenmismaking met Calvyn by die teologiese opleidings kan in hierdie verband ' $n$ belangrike bydrae lewer.

Soos reeds eerder vermeld, mag die ortodoksie nie ten koste van die ortopraksie ter sprake kom nie. Die diakonia mag nooit deur die kerk vergeet word nie. Wie alleen die valse apostels elimineer, maar liefde vergeet, het geen toekoms nie (Op. 2:1-7).

\subsection{Die institusionalistiese kerk}

Institusionalisme is nie 'n nuwe verskynsel nie: reeds die Ou-Testamentiese profete moes hierteen en teen fornalisme te velde trek. Die kultus en offerdiens 
het naamlik seepglad verloop maar die lewe op straat het gesterf (1 Sam. 15:22; Jer. 7:21-22; Hos. 6:6; 4:2; Miga 6:6). So ook moes Christus Hom teen die institusionalisme van die Fariseërs verset (Matt. 23:23).

Die institusionalistiese kerk is die kerk wat meen dat as sy kerkorde suiwer en sy liturgie sober is en sy eredienste rustig verloop, alles in orde is. So 'n kerk is gearriveerd, klaar in die Nuwe Jerusalem en sien nie meer die voortdurende terugkeer na die Woord, nee, na Gód, raak nie. Dit is dán dat mense begin kla oor koudheid in die kerk, 'n gebrek aan wannte, meelewendheid en die dra van mekaar se laste. Samevattend: 'n gebrek aan koinonia.

In ' $n$ institusionalistiese kerkbeskouing word oormatig veel aandag aan vergaderings bestee: kerkraadsvergaderings, klassisvergaderings en sinodevergaderings. Kerkwees gaan op in vergadering-wees. Sinodalisme loer om die hoek. Vroeg en laat word gevra: Wat sê die sinode? Daar word al minder gevra na wat die Bybel sê of hoe die sinode die Bybel verstaan. Die swaartepunt van kerkwees verskuif van die plaaslike gemeente met sy koinonia na vergaderings met hulle besluite; wég van plaaslike gemeente na buro's en rade, deputate en kommissies.

Hierdie gevaar van institusionalisme sien ons nie net in die Rooms-Katolieke Kerk met sy hiërargiese kerkstruktuur, waarteen die Hervormers hulle so fel verset het nie; ons sien die gevaar ook in die Gereformeerde Kerke. Dit is wel waar dat die verskeurde kerklike situasie met sy kerklike afgrensing teenoor mekaar hierdie euwel vergroot het, maar dit doen niks afbreuk aan die feit dat voortdurend teen alle vorme van kerklike institusionalisme geveg moet word nie. Let wel, daar moet nie standpunt ingeneem word teen die institusionele aard van die kerk nie, want daarsonder word die kerk 'n skim, maar wél teen die ooraksentuering van hierdie institusionele aard.

Ek meen dat die ouer kerke in hierdie opsig veel kan leer van die jonger kerke met hulle minder formalistiese inslag.

\subsection{Die skeurende kerk}

In die Bybel is dit so helder soos daglig dat daar maar net éen kerk van God op aarde kan wees. Een Herder kan maar net één kudde hê (Joh. 10:16) en die wêreld kan alleen in Christus glo as hulle iets van die wesentlike eenheid in die kerk sien (Joh. 17:21). Dit is ondenkbaar om te sê dat ek van Paulus is, of van Apollos, of van Petrus, of van Christus (1 Kor 1:12), om te sê ek is van Augustinus of Aquinas, van Luther of Calvyn, van Barth of Berkhof, van Postma of Van der Hoff. 
Daar is maar een liggaam en een Gees, een Here, een geloof, een doop, een God en Vader (Efes. 4:4-6). Ons kan dus onmoontlik van die konklusie wegkom dat kerklike versteurdhede sónde is en 'n gruwel in die oë van die Here - hoe pynlik ervaar ons nie vandag in Suid-Afrika hierdie gebrek aan eenheid te midde van soveel krisis nie. Die Hervormers was korrek in hul kritiek op die Roomse pous as aardse hoof naas Christus as hemelse Hoof van die kerk; 'n liggaam met twee koppe is ' $n$ gedrog - maar hulle het nie raakgesien dat een Hoof met baie liggame óók ' $n$ gedrog is nie. Die eenheid van die kerk is net so 'n waarheid soos sy heiligheid, apostolisiteit en katolisiteit. 'n Onenige kerk is ' $n$ innerlike weerspreking.

Natuurlik was skismatisme deur alle eeue heen 'n lewende gevaar vir die kerk. Reeds die verdeling van Juda en Israel in 722 v.C. moet as kerkskeuring getipeer word - 'n skeuring wat later gelukkig weer geheel is. Selfs die Vroeë Kerk het sy skeurings gehad. Marcionisme in die tweede eeu (in die vyfde eeu het dit verdwyn); Montanisme, ook in die tweede eeu (verdwyn in die vierde eeu); Donatisme in die derde eeu - in Afrika was dit selfs groter as die Katolieke Kerk Al hierdie bewegings het egter doodgeloop, hoewel sekere tendense hiervan die kerk deur alle eeue heen bygebly het.

Van groter allure was dié breuk in 1054 tussen die Oosterse en Westerse kerke asook dié vall die sestiende eeu in die Westerse kerk toe Rome en Reformasie uiteengegaan het. Terwyl Rome min of meer daarin geslaag het om die eenheid te bewaar, het die Reformatoriese kerke uitmekaar gespat op 'n wyse wat selfs 'n verskietende ster laat verbleek. Dan word nie eers melding gemaak van die talle sektes en kerkagtige groeperings waarvan Afrika en in besonder Suid-Afrika so vol is - na bewering oor die 6000 .

Die twintigste eeu word gekenmerk deur die opkoms van 'n hele aantal 'teologieë': die bevrydingsteologie, die charismatiese teologie én die ekumeniese teologie. Dit word dan ook die eeu waartydens 'n hele aantal ekumeniese bewegings ontstaan: die Gerefonneerde Ekumeniese Sinode (tans Raad) in 1946, die Wêreldraad van Kerke in 1948, die Internasionale Raad van Christelike Kerke in 1948, die Internasionale Konferensic van Gerefonmeerde Kerke in 1982 (die Wêreldbond van Gerefonmeerde Kerke is reeds in 1875 gestig). Wat Afrika betref, kan gedink word aan die All African Conference of Churches en in SuidAfrika aan die Suid-Afrikaanse Raad van Kerke.

Dit is baie jammer, hoewel onvernydelik, dat die jong Christene in Afrika die evangelie van Christus uit soveel monde moet hoor. Ek meen dat hierdie feit nadelig inwerk op die evangelieverkondiging; tog kan ons ons daarin verbly dat Christus verkondig word, al is dit op allerlei wyse (vgl. Fil. 1:18). Jong Christene en jong kerke kan myns insiens 'n belangrike bydrae lewer om ons te help om die verlore eenheid weer te probeer terugvind - natuurlik op die basis van die waar- 
heid. Trouens, hierdie motief (van eenheid) is nie net suiwer Bybels geïnspireer nie, maar kom ook uit die hart van die Reformasie: Calvyn was bereid on tien see daarvoor deur te vaar! Laat ons dus uiters versigtig wees om vandag oorhaastig van kerkskeuring of kerkafskeiding te praat, gedagtig aan die voorbeeld van Jesus wat sy eiendom, die kerk, tot die eindeiuterste liefgehad het (Joh. 13:1).

\section{Konklusie}

Ek het in hierdie perspektief op die kerkgeskiedenis tematies heen en weer beweeg en dus nie die kerkgeskiedenis in chronologiese volgorde behandel nie. Ek meen dat ons op hierdie wyse ook iets uit die kerkgeskiedenis vir ons situasie van vandag kan leer.

Sonder om te oordryf meen ek dat die kerk in ons Suid-Afrikaanse situasie een van die sleutels vir 'n oplossing van ons probleme in sy hand het: die verkondiging én uitlewing van die evangelie van versoening. Dan moet die kerk egter waarlik kérk wees. 